\title{
Photoreceptor Protection by Mesencephalic Astrocyte-Derived Neurotrophic Factor (MANF)
}

\author{
Jianmin Lu, ${ }^{1,2,}$, Lingyu Luo, ${ }^{1,3,}$, Deqiang Huang, ${ }^{1,3}$ Xian Liu, ${ }^{4}$ Xin Xia, ${ }^{1}$ Zhengying Wang, ${ }^{1}$ Byron L. Lam, ${ }^{1}$ \\ Jinglin $\mathrm{Yi}^{4}{ }^{4}$ Rong Wen, ${ }^{1}$ and $\mathrm{Yiwen}^{\mathrm{Li}}{ }^{1}$
}

DOI:http://dx.doi.org/10.1523/ENEURO.0109-18.2018 ${ }^{1}$ Bascom Palmer Eye Institute, University of Miami, Miller School of Medicine, Miami, FL 33136, ${ }^{2}$ Department of
Ophthalmology, First Affiliated Hospital, Dalian Medical University, Dalian, 116011, China, ${ }^{3}$ First Affiliated Hospital,
Nanchang University, Jiangxi Medical School, Nanchang, 330006, China, and ${ }^{4}$ Eye Hospital, Nanchang University,
Jiangxi Medical School, Nanchang, 330006, China

\begin{abstract}
Retinal degenerations are a major cause of vision impairment and blindness. Neuroprotective therapy is a promising therapeutic strategy for retinal degenerative diseases. We investigated a novel neurotrophic factor mesencephalic astrocytederived neurotrophic factor (MANF) in the retina. MANF is expressed at a high level during postnatal development and the expression declines to a lower level as the retina matures. Müller cells are the major cells expressing MANF. It is also found in the retinal ganglion cells, in the inner nuclear layer (INL) neurons, and in retinal pigment epithelial (RPE) cells. Intravitreal injection of recombinant human (rh)MANF significantly protected rod and cone photoreceptors in rats carrying the rhodopsin S334ter mutation, and preserved electroretinograms (ERGs) in the rd10 (Pde6b ${ }^{\text {rd10/rd19 }}$ mice. These results indicate that MANF is a native protein in the retina and is a potent neurotrophic factor for photoreceptor protection.
\end{abstract}

Key words: degeneration; MANF; neuroprotection; photoreceptor; retina; RGC

\section{Significance Statement}

This is a study of high translational value to examine the neuroprotective potential of a novel neurotrophic factor mesencephalic astrocyte-derived neurotrophic factor (MANF) in the retina. MANF is expressed in the retina at high level during postnatal development and then declines as the retina matures. Recombinant MANF protects rod and cone photoreceptor cells and preserves electroretinograms (ERGs). These results suggest a role of MANF in the retinal development and provide preclinical evidence for further development of MANF as a neuroprotective agent as a potential treatment for retinal degenerative disorders.

\section{Introduction}

Retinal degenerations are a major cause of vision impairment and blindness (Hartong et al., 2006). Retinitis pigmentosa (RP), a most common inherited retinal degeneration, affects one in $3500-4000$ people. Mutations in more than at least 60 genes (as of February 2018) are identified to be associated to RP (RetNet, 2018). Yet in many RP cases, the causative mutations remain unidentified (Hartong et al., 2006).

Received March 21, 2018; accepted April 9, 2018; First published April 16, 2018.

R.W. has been named as the inventor in a patent application filed by the University of Miami that covers the intellectual property presented in this paper. All other authors declare no competing financial interests.
There are no specific treatments available for retinal degenerations, except a recently approved gene therapy for RPE65 related Leber's congenital amaurosis type 2 (LCA2; Food and Drug Administration, 2017). Three major treatment strategies are under intensive research: gene therapy or gene augmentation therapy, neuroprotective therapy, and retinal prostheses. In gene therapy, a copy of transgene (cDNA in most cases) encoding a normal gene product is transferred to affected cells to restore the

Author contributions: B.L.L., J.Y., R.W., and Y.L. designed research; J.L., L.L., D.H., X.L., X.X., W.Z., R.W., and Y.L. performed research; J.L., L.L., D.H., X.L., X.X., W.Z., R.W., and Y.L. analyzed data; J.L., L.L., B.L.L., J.Y., R.W., and Y.L. wrote the paper.

This work was supported by National Institutes of Health (NIH) Grants 
function of faulty gene, and thus the current therapy strategy is limited to the treatment of loss-of-function mutations in identified genes. The success of gene therapy for LCA2 proves that the function of RPE65 gene can be restored by introducing the normal RPE65 transgene into the retinal pigment epithelial (RPE) cells (Bainbridge et al., 2008; Hauswirth et al., 2008; Maguire et al., 2008). Surprisingly, the RPE65 gene therapy failed to stop the degeneration process (Cideciyan et al., 2013; Bainbridge et al., 2015; Jacobson et al., 2015). Therefore, restoration of a defect gene may not necessarily protect photoreceptors from degeneration, and there is a need for additional treatments to save photoreceptors.

Retinal prostheses are electronic implants to restore vision and to improve quality of life for patients with end-stage retinal degenerations (Cheng et al., 2017). A retinal prosthesis uses an array of electrodes to stimulate the remaining retina, which in turn conveys the signals to the brain. Due to the large size and limited number of electrodes in an array, the quality of images experienced by patients is very low. Nevertheless, the limited visual function dramatically improves the quality of life of patients with total blindness.

Neuroprotective therapy aims at delaying or halting the degenerative process in neurons by neurotrophic agents. It is a "broad spectrum" strategy to save neurons that one neurotrophic agent may be effective for degenerations caused by more than one mutant gene. In addition, a neurotrophic agent effective for photoreceptor protection may also be effective for other retinal neurons. For example, ciliary neurotrophic factor (CNTF), the best studied neurotrophic factor for retinal degenerations (Wen et al., 2012), has been investigated for a variety of neural degenerative diseases in the retina, including RP (Sieving et al., 2006; Talcott et al., 2011; Birch et al., 2013, 2016), macular degeneration (Zhang et al., 2011), and macular telangiectasia (Chew et al., 2015; Sallo et al., 2018).

Mesencephalic astrocyte-derived neurotrophic factor (MANF) is a novel neurotrophic factor originally identified as a secreted protein in the culture medium of rat mesencephalic type 1 astrocytes (ventral mesencephalic cell line 1; VMCL1) that promotes survival of rat embryonic dopaminergic neurons (Petrova et al., 2003). It protects nigrostriatal dopaminergic neurons from 6-hydroxydopamine-induced degeneration in vivo (Voutilainen et al., 2009) and brain cells

R01EY015289 and R01EY018586, Hope for Vision, the James and Esther King Biomedical Research Program of the State of Florida Grant 08KN-09, 2KF02, National Natural Science Foundation of China Grants 81560164 and 81300737, NIH Core Grants P3OEY14801 and P30EY002162, and an unrestricted grant from Research to Prevent Blindness Inc. to Bascom Palmer Eye Institute. R.W. is the recipient of the 2015 Nelson Trust Award for Retinitis Pigmentosa from Research to Prevent Blindness, Inc.

*J.L. and L.L. contributed equally to this work.

Correspondence should be addressed to Dr. Yiwen Li, McKnight Building, RM 506, Bascom Palmer Eye Institute, University of Miami, Miller School of Medicine, 1638 NW 10th Avenue, Miami, FL 33136, E-mail: yli2@med.miami.edu.

DOl:http://dx.doi.org/10.1523/ENEURO.0109-18.2018

Copyright (c) 2018 Lu et al.

This is an open-access article distributed under the terms of the Creative Commons Attribution 4.0 International license, which permits unrestricted use, distribution and reproduction in any medium provided that the original work is properly attributed.

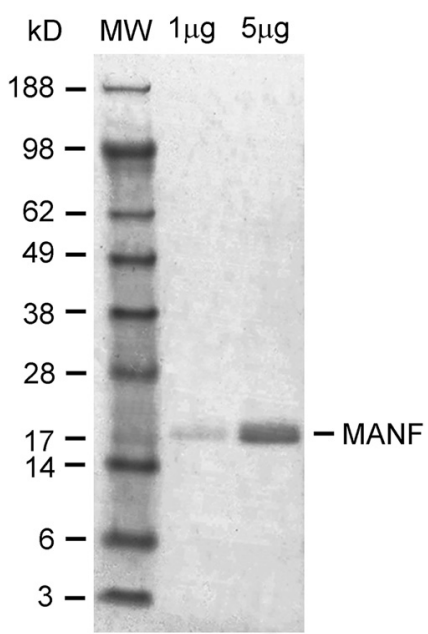

Figure 1. Expression and purification of rhMANF. The 6xhistagged protein was expressed in $E$. coli and purified on nickel columns. Purified rhMANF was detected as a single band $\sim 20$ $\mathrm{kDa}$ when electrophoresed on 4-12\% NuPAEG gel and visualized with Coomassie Blue.

in a rat stroke model (Airavaara et al., 2009). In the present work, we characterized the expression of MANF in the retina. MANF is a retinal native protein, expressed in Müller cells, RPE cells, and neurons in the inner retina. When delivered by intravitreal injection, recombinant human MANF (rhMANF) significantly protects rod and cone photoreceptors from degeneration. These results indicate that MANF is a neurotrophic factor for photoreceptors and provide evidence to support the development of MANF for treating retinal degenerative diseases.

\section{Materials and Methods}

\section{Expression and purification of rhMANF protein}

Recombinant human MANF protein expression and purification were conducted as described previously (Wen et al., 2006). The open reading frame of mature human MANF cDNA was cloned into an expression vector pQE30 (QIAGEN), fused to a $6 \mathrm{xH}$ is tag at the amino terminus to generate plasmid pQE-MANF. MANF was expressed in Escherichia coli (XL-blue, Agilent) and purified by immobilized-metal affinity chromatography on Ni-NTA Agarose columns (QIAGEN) under native conditions. Protein was eluted from the Ni-NTA columns with a buffer containing $250 \mathrm{mM}$ imidazole. The elution buffer was exchanged to phosphate buffered saline (PBS) on EconoPac 10DG columns (Bio-Rad Laboratories). The purified rhMANF in PBS was stored at $-80^{\circ} \mathrm{C}$ until use. The protein has an apparent size of $\sim 20 \mathrm{kDa}$ after electrophoresis on acrylamide gel (Fig. 1).

\section{Experimental animals}

All procedures involving animals were approved by the Animal Care and Use Committee at the University of Miami. Transgenic rats (Sprague Dawley background) carrying a murine rhodopsin mutant S334ter (line3 or S334ter-3), wild-type Sprague Dawley (Harlan Laboratories) rats, and the $r d 10\left(P d e 6 b^{r d 10 / r d 10}\right)$ mice that carry a missense mutation in the Pde6b (cGMP phosphodiester- 
ase 6B; The Jackson Laboratory), were kept in a 12/12 h light/dark cycle at an in-cage illumination of $<50$ lux. The room temperature was maintained at $20-22^{\circ} \mathrm{C}$. Heterozygous S334ter-3 rats were produced by mating homozygous male breeders with wild-type Sprague Dawley females. Animals of both sexes were used in the experiments.

\section{Intravitreal injections}

Intravitreal injections were delivered through 33-gauge needles connected to $10-\mu \mathrm{l}$ microsyringes (Hamilton Company), as described previously (Wen et al., 2006). The right eye of an animal was injected with rhMANF protein and the left eye with the equivalent volume of PBS.

\section{Histology}

Retinal structure was examined with semi-thin sections. Animals were killed by $\mathrm{CO}_{2}$ overdose, immediately followed by vascular perfusion with mixed aldehydes (LaVail and Battelle, 1975). Eyes were embedded in an Epon/ Araldite mixture, sectioned at $1 \mu \mathrm{m}$ thickness to display the entire retina along the vertical meridian (LaVail and Battelle, 1975). Retinal sections were stained with $1 \%$ toluidine blue and examined by light microscopy.

\section{Western blotting}

To examine MANF expression levels by Western blot analysis, retinas were harvested after animals were killed by $\mathrm{CO}_{2}$ overdose. Pooled retinas were homogenized in a lysis buffer that contained $50 \mathrm{mM}$ Tris, $150 \mathrm{mM} \mathrm{NaCl}, 1 \% \mathrm{NP}-40$, $0.1 \%$ sodium dodecyl sulfate, $20 \mathrm{nM}$ calyculin $\mathrm{A}, 100 \mathrm{mM}$ phenylmethylsulfonyl fluoride, $10 \mu \mathrm{g} / \mathrm{ml}$ leupeptin, and 10 $\mathrm{ng} / \mathrm{ml}$ aprotinin. Protein concentration in each sample was determined by the BCA protein assay (Bio-Rad Laboratories). Total protein of samples was electrophoresed on 4-12\% NuPage gel (ThermoFisher Scientific) and transferred to nitrocellulose membranes (Bio-Rad Laboratories). Western blotting was performed using rabbit anti-MANF antibodies (1:1000 dilution, MilliporeSigma) and mouse anti$\beta$-actin antibodies (1:5000, dilution, MilliporeSigma), followed by appropriate secondary antibody conjugated to horseradish peroxidase (HRP). Signals were visualized using chemiluminescent substrates (ThermoFisher Scientific) and recorded on Hyperfilm (GE Healthcare). All experiments were repeated 3 times to verify the consistency of the results.

\section{Immunocytochemistry}

Immunocytochemical experiments were performed on cryo-sections. Eyes were removed after animals were perfused with $4 \%$ paraformaldehyde. Eyecups were prepared, cryo-protected with $30 \%$ sucrose, and frozen in Tissue-Tek OCT compound (Miles Inc.). Cryo-sections of $12 \mu \mathrm{m}$ were cut along the vertical meridian on a Cryostat (CM1900, Leica Biosystems), incubated with rabbit anti-MANF antibodies (1:400 dilution, MilliporeSigma), and with mouse antiglutamine synthetase (GS; 1:100 dilution, MilliporeSigma) to identify Müller cells. MANF and GS immunoreactivities were visualized by Cy2- and Cy3-conjugated secondary antibodies (Jackson ImmunoResearch), respectively, and examined by confocal microscopy.

\section{Retina-lens preparations and peanut agglutinin (PNA) staining}

Retina-lens preparations were used for PNA staining to identify cone outer segments (COSs), as described previously (Li et al., 2010). Eyes were removed from animals after $\mathrm{CO}_{2}$ overdose and cardiac perfusion with PBS. Retina-lens preparations were obtained by first removing the cornea along the limbus. A small cut was made at the edge of sclera toward the posterior pole. With two pairs of forceps placed one at each side of the cut, the sclera, along with the choroid and RPE was carefully torn open. The sclera-choroid-RPE was peered to the base of optic nerve, and cutoff. The resulted retina-lens preparations were post-fixed in $4 \%$ paraformaldehyde solution at $4^{\circ} \mathrm{C}$ for $4 \mathrm{~h}$.

PNA, which binds to COSs (Blanks and Johnson, 1983; Hageman and Johnson, 1986; Li et al., 2010), was used to identify cone photoreceptors. For staining, retina-lens preparations were incubated with Alexa Fluor 488conjugated PNA (ThermoFisher) for $1 \mathrm{~h}$. The lenses were removed and the retinas were flat-mounted on slides and examined by confocal microscopy. Cone cells were counted in the superior retina.

\section{Electroretinogram (ERG) recording}

ERGs were recorded with a UTAS system (LKC Technologies). After dark adapted overnight, mice were anesthetized with intraperitoneal ketamine $(80 \mathrm{mg} / \mathrm{kg})$ and xylazine $(4 \mathrm{mg} / \mathrm{kg})$ under dim red light. Pupils were dilated with $0.1 \%$ atropine and $0.1 \%$ phenylephrine $\mathrm{HCl}$. During the recording, animals were on a heat pad to maintain body temperature at $37^{\circ} \mathrm{C}$. A contact lens electrode was placed on the cornea of each eye, a differential electrode under the skin of the forehead, and a ground wire electrode under the skin close to the base of the tail. Both eyes were recorded simultaneously. Full field ERGs were elicited by 1-ms white flashes generated by white LEDs in the Ganzfeld sphere. Inter-stimulus intervals were $10 \mathrm{~s}$. Each recording was an average of 10 responses. The b-wave amplitudes of the treated eyes were compared with the control eyes.

\section{Experimental design and statistic analysis}

All means are presented as mean \pm SD. A minimal number of animals to be used in each experiment was determined by our previous experience on similar experiments and power analysis based on $\alpha=0.05$ at $80 \%$ statistical power. Data analyses were performed using InStat (version 3.0, GraphPad Software Inc.). Results were evaluated by Student's $t$ test for comparisons between two experimental groups.

\section{Results}

\section{Expression and localization of MANF protein in the retina}

The expression of MANF protein was examined in the retinas of Spraque Dawley rat at postnatal day $(\mathrm{PD}) 1$, PD5, PD8, PD10, PD12, PD16, PD20, PD25, PD30, PD40, and PD60 by Western blot analysis. High level of MANF protein expression was detected in the rat retina from PD1 


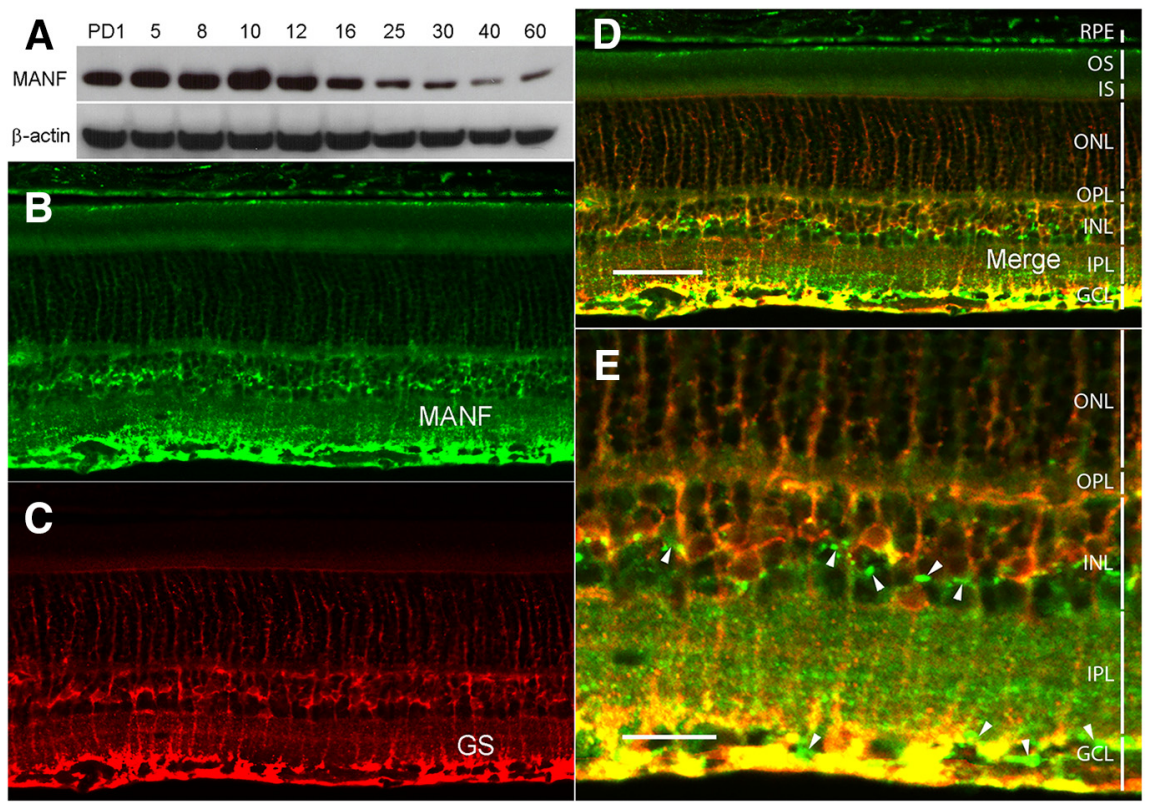

Figure 2. Expression of MANF in the retina. $\boldsymbol{A}$, Expression of MANF during postnatal development. Retinas were collected at designated time points from wild-type Sprague Dawley rats. Levels of MANF were detected by Western blot analysis with anti-MANF antibodies. High levels of MANF expression were detected during postnatal development (from PD1 to PD16; $\boldsymbol{A}$, upper panel). As the retinas mature, the expression decreases (from PD25 to PD60; $\boldsymbol{A}$, upper panel). The same blot was reprobed with anti- $\beta$-actin antibodies as loading controls $(\boldsymbol{A}$, lower panel). Cryosections of $12 \mu \mathrm{m}$ of eyes of PD20 wild-type Sprague Dawley rats along the vertical meridian were stained with anti-MANF antibodies $(\boldsymbol{B}, \boldsymbol{D}, \boldsymbol{E})$. Müller cells were identified by antibodies against $\mathrm{GS}(\boldsymbol{C}-\boldsymbol{E})$. Extensive colocalization of MANF and GS immunoreactivities $(\boldsymbol{D}, \boldsymbol{E}$, yellow) indicates that MANF in the retina is expressed in Müller cells. RPE cells, neurons in the GCL, and neurons in the INL also display MANF immunoreactivities $(\boldsymbol{B}, \boldsymbol{D}$, white arrowheads in $\boldsymbol{E})$. OS, outer segments; IS, inner segments; OPL, outer plexiform layer; IPL, inner plexiform layer. Scale bar: $50 \mu \mathrm{m}(\boldsymbol{D})$ and $20 \mu \mathrm{m}(\boldsymbol{E})$.

to PD16 with the highest level at PD10. The expression declines to lower levels from PD25 to PD60, as the retina matures (Fig. 2A).

MANF was localized in retinal cells by immunostaining in cells in the inner nuclear layer (INL), the retinal ganglion cell layer (GCL), and the RPE layer (Fig. 2B,D,E). Double staining of MANF and GS, a Müller cells marker, shows extensive colocalization of MANF and GS immunoreactivities, indicating most of the MANF in the INL is in Müller cells (Fig. 2C,D,E). MANF immunoreactivity was also detected in neurons in the INL and the GCL (Fig. 2B,D,E, white arrowheads) and in the RPE cells (Fig. 2B,D). Although MANF is a secreted protein, it contains an endoplasmic reticulum (ER) retention sequence $R T D L$ at the C-terminal end to allow MANF retained in the ER in the cells that express it (Henderson et al., 2013). A certain amount of MANF should remain in MANF-expressing cells to be detected by immunocytochemical experiments. It is therefore very likely that MANF-positive cells are MANFexpressing cells.

\section{Protection of rod photoreceptor by MANF treatment}

We examined the potential protective capability of MANF on photoreceptors in heterozygous S334ter-3 rats. Photoreceptors in those animals undergo rapid degenerate starting around PD10 and by PD20, most of the rod photoreceptors are lost (Liu et al., 1999). Rod outer segments fail to develop in the S334ter-3 rats, and the scotopic ERGs are undetectable. MANF was injected intravitreally to the right eyes of S334ter-3 rats $(6 \mu \mathrm{g}$ in 3 $\mu l$ of PBS) at PD9, and the left eyes were injected with 3 $\mu l$ of PBS as controls. Eyes were collected by PD20 for histologic analysis. As shown in Figure $3 A$, the outer nuclear layer (ONL) of the superior retina in the control eyes had only one row of nuclei. In the treated eyes, however, the ONL in the superior retina had three to four rows of cell nuclei (Fig. 3B). In comparison, the ONL in a normal PD20 rat has 13-14 rows of photoreceptor nuclei (Fig. 3C). Quantitative analysis of the ONL thickness, measured $200 \mu \mathrm{m}$ from the optic nerve head in the superior retina, shows that the ONL in treated retinas $(17.47 \pm 3.96$ $\mu \mathrm{m}, n=5)$ are significantly thicker than the control retinas (7.07 $\pm 1.12 \mu \mathrm{m}, n=5 ; p<0.001$, Student's $t$ test; Fig. 3D).

\section{Protection of cone photoreceptors by MANF}

The significant protective effect of rhMANF on rod photoreceptors encouraged us to examine the potential protective effect of rhMANF on cone photoreceptors. Cone photoreceptors in the S334ter-3 rats undergo significant secondary cone degeneration, characterized by loss of COSs in numerous PNA-negative patches throughout the retina (Li et al., 2010). We injected rhMANF (6 $\mu \mathrm{g}$ in $3 \mu \mathrm{l}$ of $\mathrm{PBS}$ ) intravitreally to the right eyes of S334ter-3 rats at PD20 when rod degeneration is mostly complete, and secondary cone degeneration is already significant $(\mathrm{Li}$ et al., 2010). The left eyes were injected with PBS as controls. Retinas were harvested at PD30 and stained with PNA. Many PNA-negative patches are present in the control retinas (Fig. 4A). In MANF-treated retinas, the 


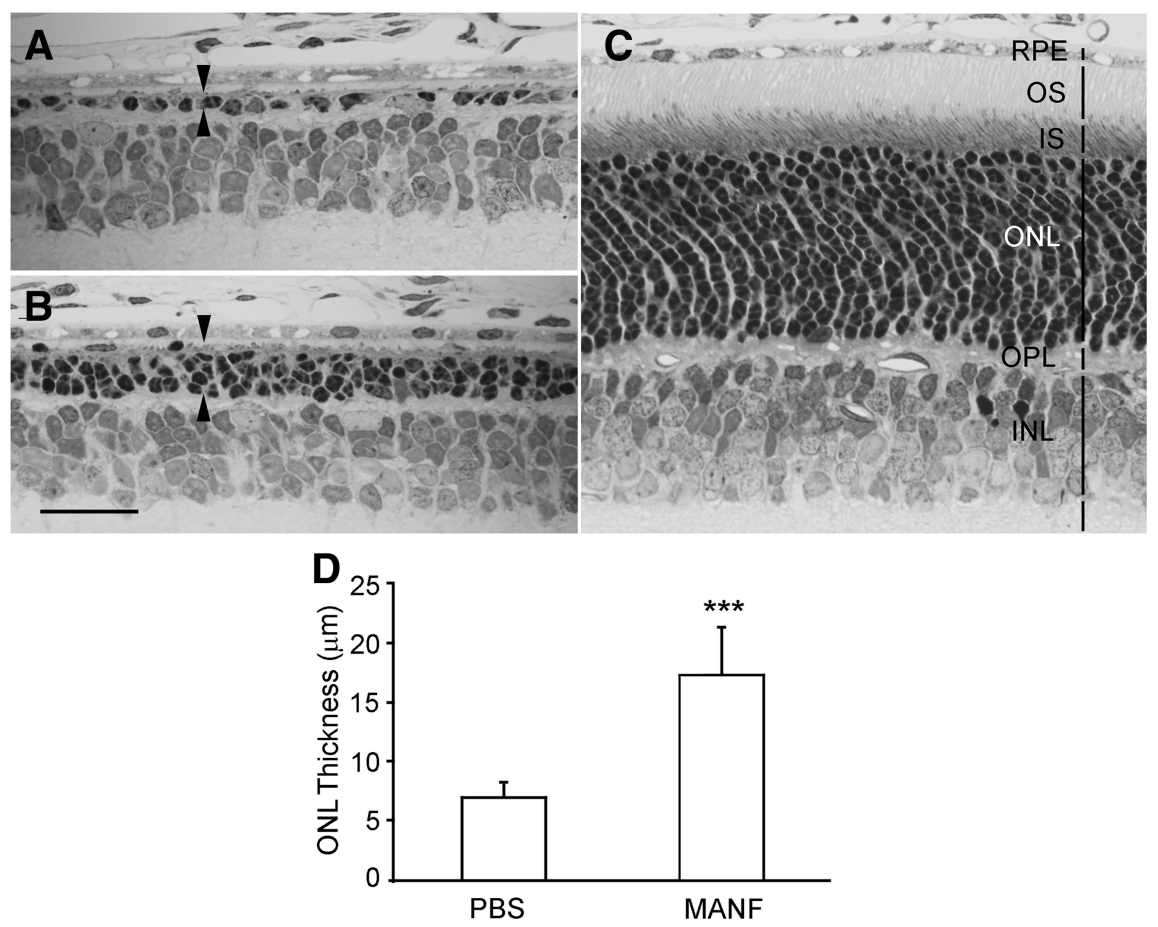

Figure 3. Protection of rod photoreceptors by MANF. The right eyes of S334ter-3 rats were treated with $6 \mu \mathrm{g}$ (in $3 \mu \mathrm{l}$ of PBS) of MANF by intravitreal injection, and the left eyes were injected with of PBS. Tissues were collected at PD20. Semi-thin sections were cut and stained with toluidine blue. The ONL in the control eye had only one row of nuclei in the superior retina (between arrowheads, $\boldsymbol{A}$ ), whereas in the eyes treated with MANF, there are three to four rows of nuclei in the ONL (between arrowheads, $\boldsymbol{B}$ ). In comparison, the ONL in a normal wild-type rat at PD20 contains 13-14 rows of nuclei $(\boldsymbol{C})$. Quantitative analysis shows that the ONL in the MANF-treated retinas (superior retina) is significantly thicker than that in the PBS-treated retinas $(\boldsymbol{D}$, triple asterisks indicate $p<0.001$, Student's $t$ test). OS, outer segments; IS, inner segments; OPL, outer plexiform layer. Scale bar: $25 \mu \mathrm{m}$.

PNA-negative areas are very small and in many cases are not present (Fig. 4B). Quantitative analysis showed that PNA-positive cells are significantly more in rhMANFtreated retinas $(569.5 \pm 46.5, n=6)$ than in PBS-treated retinas $(398.7 \pm 25.4, n=6 ; p<0.001$, Student's $t$ test; Fig.4C). These results indicate that MANF is also a potent neurotrophic factor for cone photoreceptors.

\section{ERG preservation by rhMANF treatment}

We used the rd10 mice, which carry a missense mutation in the Pde6b gene, to investigate the potential capacity of MANF to preserve the function of photoreceptors. The rod ERGs are suppressed in the rd10 mice but measurable (Chang et al., 2002). In the ERG experiment, the left eyes were intravitreally injected with $2 \mu \mathrm{g}$ of MANF (in $1 \mu \mathrm{l}$ of PBS) at PD18, and the right eyes were injected with $1 \mu \mathrm{l}$ of PBS to as controls. Full field ERGs were recorded from both eyes simultaneously at PD28. Scotopic ERG b-wave was reliably evoked by white light flashes of -0.4 $\log \mathrm{cd}-\mathrm{s} / \mathrm{m}^{2}$, although the a-waves were undetectable (Fig. 5A). The average amplitude of b-wave from rhMANFtreated eyes is $115 \pm 16.5 \mu \mathrm{V}$ (mean $\pm \mathrm{SD}, n=5$ ), significantly higher than the average amplitude of the b-wave from PBS treated control eyes of $82.4 \pm 10.7 \mu \mathrm{V}$ $(n=5 ; p=0.017$, Student's $t$ test; Fig. $5 B$ ).

\section{Discussion}

We have investigated the spatial and temporal expression patterns of MANF in the retina, and the neuroprotec- tive potential of MANF on photoreceptors. MANF is expressed in the retina at high levels during postnatal development. As the retina matures, the expression declines to lower levels. This temporal expression pattern in the retina is similar to the expression pattern of MANF in the cerebral cortex (Wang et al., 2014), suggesting the importance of MANF during the postnatal development and maturation of the retina and the brain. The extensive colocalization of MANF and GS immunoactivities shows that Müller cells are the major MANF-expressing cells and the major source of MANF in the retina.

The potency of MANF as a neurotrophic factor for photoreceptors is highlighted by the significant protection of photoreceptors. The rapid photoreceptor degeneration in the S334ter-3 rats (Liu et al., 1999) favors experiments to test purified protein factors, which could be degraded rapidly after intravitreal injection. Therefore this model ensures that only neurotrophic factors with enough potency could yield positive results. On the other hand, false negative results could occur when a factor with lower potency is tested. We used the S334ter-3 rats in our previous studies on photoreceptor protection by neurotrophic factors in the interleukin-6 family of neurotrophic cytokines, including CNTF, cardiotrophin-1 (CT-1), and oncostatin M (OsM); (Tao et al., 2002; Song et al., 2003; Xia et al., 2011).

In addition, rhMANF protects the function of photoreceptors, as indicated by the significantly preservation of 

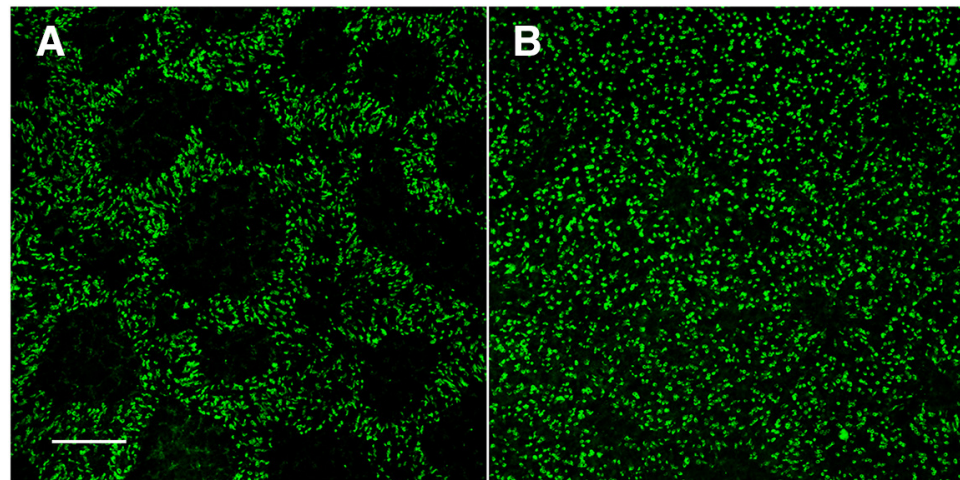

C

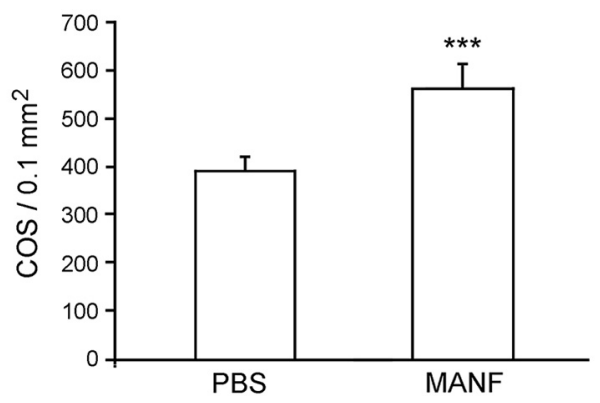

Figure 4. Protection of cone photoreceptors by MANF. The right eyes of S334ter-3 rats were treated with $6 \mu \mathrm{g}$ (in $3 \mu \mathrm{l}$ of PBS) of MANF by intravitreal injection, and the left eyes were injected with of PBS at PD20. Eyes were harvested $10 \mathrm{~d}$ after injection (PD30). Retinas were stained with PNA to identify cone outer segments. In the control retinas treated with PBS, many PNA-negative patches are present $(\boldsymbol{A})$. In MANF-treated retinas, PNA-negative patches were very small and in many areas are not present $(\boldsymbol{B})$. Quantitative analysis of PNA-positive cells in the superior retinas are significantly more in MANF-treated eyes $(569.5 \pm 46.5, n=6)$ than in PBS-treated eyes $(398.7 \pm 25.4, n=6$; $\boldsymbol{C}$, triple asterisks indicate $p<0.001$, Student's $t$ test). Scale bar: $100 \mu \mathrm{m}$.

ERGs in the rd10 mice. The rd10 mouse carries the p.R560C mutation in the Pde6b gene that leads to suppressed rod ERG and photoreceptor degeneration (Chang et al., 2002, 2007). The relatively late onset and milder degeneration in the rd10 mouse makes it a preferred model for pre-clinical studies of retinal functions, including gene therapy trials (Pang et al., 2008, 2011), long-term neurotrophic factor study (Ohnaka et al., 2012), and small molecular compound treatment trials (Phillips et al., 2008; Kang et al., 2016).

MANF, also known as arginine-rich, mutated in early stage of tumors (Armet), is originally identified as a secreted protein in the culture medium of rat mesencephalic type 1 astrocytes that promotes survival of rat embryonic dopaminergic neurons (Petrova et al., 2003). It has no significant homology to any known neurotrophic factors and thus MANF is regarded as a novel neurotrophic factor, the founding member of a new family of neurotrophic factors (Lindholm and Saarma, 2010). A second member of the family, cerebral dopamine neurotrophic factor (CDNF), was identified a few years later (Lindholm et al., 2007). MANF is expressed in many areas in the CNS, including many brain regions and the spinal cord (Lindholm et al., 2008; Wang et al., 2014). It promotes survival of rat embryonic dopaminergic neurons in vitro (Petrova et al., 2003) and nigrostriatal dopaminergic neurons from 6-hydroxydopamine-induced degeneration in vivo (Voutilainen et al., 2009). Intracerebral injection of purified MANF reduces the volume of infarction and improves

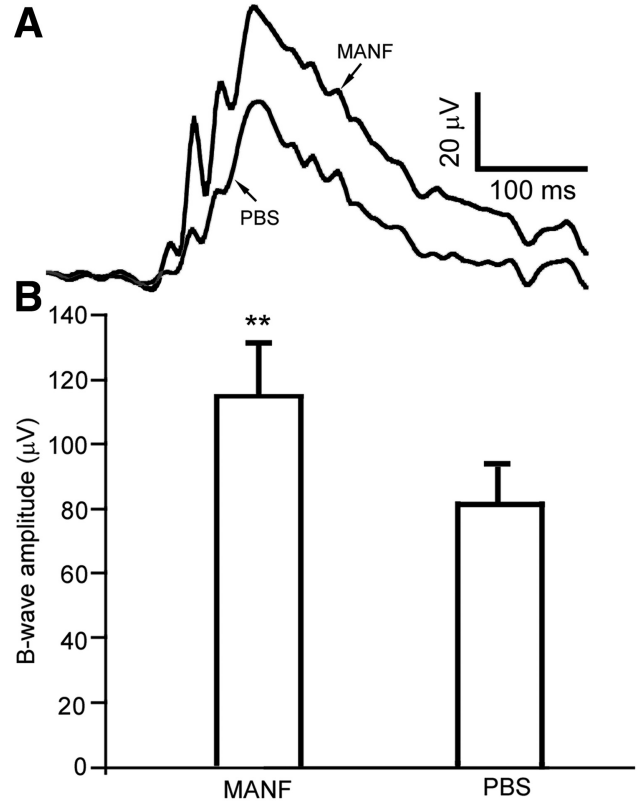

Figure 5. Preservation of ERG by MANF. The right eyes of $r d 10$ mice were treated with $2 \mu \mathrm{g}$ (in $1 \mu \mathrm{l}$ of PBS) of MANF by intravitreal injection at PD18. The left eyes were treated with PBS. ERGs were recorded from both eyes simultaneously $10 \mathrm{~d}$ later at PD28. Scotopic b-waves evoked by white light flashes of $-0.4 \mathrm{log} \mathrm{cd}-\mathrm{s} / \mathrm{m}^{2}$ were reliably recorded but the a-waves were undetectable $(\boldsymbol{A})$. Significantly higher b-wave amplitudes were recorded from MANF-treated eyes, with an average amplitude of $115 \pm 16.5 \mu \mathrm{V}(n=5)$, as compared with PBS-treated eyes whose average amplitude is $82.4 \pm 10.7 \mu \mathrm{V}(n=5 ; \boldsymbol{B}$, double asterisks indicate $p=0.0017$, Student's $t$ test). 
behavior recovery in a rat stroke model (Airavaara et al., 2009).

In addition to the CNS, MANF is found in the liver, the salivary gland, and the testis (Lindholm et al., 2008), suggesting that MANF also functions outside the CNS. Genetic ablation of the MANF gene in mouse results in progressive postnatal reduction of $\beta$-cell mass and severe diabetes (Lindahl et al., 2014), indicating that MANF is required for pancreatic $\beta$-cell proliferation and survival. $\mathrm{A}$ human patient with a mutation in the MANF gene has been reported to suffer from type-2 diabetes mellitus, hypothyroidism, primary hypogonadism, short stature, mild intellectual disability, obesity, deafness, high myopia, microcephaly, and partial alopecia (Yavarna et al., 2015), highlighting the roles MANF in many organs.

MANF is reported to interact with immune cells, and the interaction is shown to promote the integration of transplanted photoreceptor precursors, and to protect photoreceptors from light damage (Neves et al., 2016). However, the neurotrophic activity of MANF is independent of its interaction with immune cells, as it was originally identified in the conditional medium of VMCL1 astrocytes to protect dopaminergic neurons in an in vitro ventral mesencephalic neuroprotective assay (VMN assay) with no immune cells present (Panchision et al., 1998). The VMN assay was also used in the subsequent purification of MANF (Petrova et al., 2003). It is unlikely that the significant photoreceptor protection by recombinant MANF shown in the present study was resulted from interaction with immune cells. We recently observed interaction of MANF with Müller in the retina in vivo, and similar interaction was observed in cultured Müller cells in vitro with no immune cells present (R. Wen and $\mathrm{Y}$. Li, unpublished observations).

The mechanism underlying the neurotropic effects of MANF is not clearly understood, and the putative receptor on the cell surface to interact with secreted MANF remains unknown (Voutilainen et al., 2015; Lindahl et al., 2017). MANF was reported to induce PKC phosphorylation in PC12 cells in vitro and cerebellum Purkinje cells in vivo (Yang et al., 2014). Structurally, MANF has two domains, the $\mathrm{N}$-domain (amino-domain) and the $\mathrm{C}$-domain (carboxyl-domain), which are believed to have distinct functions (Parkash et al., 2009; Lindahl et al., 2017). The $\mathrm{N}$-domain is homologous to saposin-like proteins and is believed to have the extracellular neurotrophic activity. The C-domain is homologous to SAF-A/B, Acinus and PIAS (SAP) protein superfamily (Parkash et al., 2009; Lindahl et al., 2017).

MANF C-domain has been studied in details. It has a RTDL sequence for ER retention and is thought to function in ER stress response (Parkash et al., 2009; Lindahl et al., 2017). In addition, the CKGC motif in the C-domain, which forms the cysteine bridge, is involved in neuroprotection. Furthermore, the SAP domain is capable of inhibiting BAX-mediated apoptosis (Parkash et al., 2009; Liu et al., 2015; Mätlik et al., 2015; Lindahl et al., 2017). The C-domain is neuroprotective when expressed intracellularly (Hellman et al., 2011). Whether it can exert its neuroprotective activity when applied extracellularly remains to be studied. The N-domain is not well studied, and little is known about its functional role in neuroprotection.

In summary, we have shown that MANF is a retinal native protein expressed at high levels in early postnatal development. Müller cells are the major MANF-expressing cells, and neurons in the inner retina also express MANF. Intravitreal injection of rhMANF significantly protects both rod and cone photoreceptors, demonstrating that MANF is a potent neurotrophic factor for photoreceptors. These results provide experimental evidence to consider MANF as a neuroprotective agent for photoreceptor degenerative disorders, including RP and age-related macular degeneration. Further studies to understand the function of MANF N-domain could shed light on the extracellular neurotrophic activity of MANF. Identifying the cell surface receptors of MANF could lead to a better understanding of the molecular mechanism(s) that mediate MANF neurotrophic activity.

\section{References}

Airavaara M, Shen H, Kuo CC, Peränen J, Saarma M, Hoffer B, Wang Y (2009) Mesencephalic astrocyte-derived neurotrophic factor reduces ischemic brain injury and promotes behavioral recovery in rats. J Comp Neur 515:116-124. CrossRef Medline

Bainbridge JW, Smith AJ, Barker SS, Robbie S, Henderson R, Balaggan K, Viswanathan A, Holder GE, Stockman A, Tyler N, PetersenJones S, Bhattacharya SS, Thrasher AJ, Fitzke FW, Carter BJ, Rubin GS, Moore AT, Ali RR (2008) Effect of gene therapy on visual function in Leber's congenital amaurosis. N Engl J Med 358:22312239. CrossRef

Bainbridge JW, Mehat MS, Sundaram V, Robbie SJ, Barker SE, Ripamonti C, Georgiadis A, Mowat FM, Beattie SG, Gardner PJ, Feathers KL, Luong VA, Yzer S, Balaggan K, Viswanathan A, de Ravel TJ, Casteels I, Holder GE, Tyler N, Fitzke FW, et al. (2015) Long-term effect of gene therapy on Leber's congenital amaurosis. N Engl J Med 372:1887-1897. CrossRef Medline

Birch DG, Weleber RG, Duncan JL, Jaffe GJ, Tao W; Ciliary Neurotrophic Factor Retinitis Pigmentosa Study Groups (2013) Randomized trial of ciliary neurotrophic factor delivered by encapsulated cell intraocular implants for retinitis pigmentosa. Am J Ophthalmol 156:283-292.e281. CrossRef

Birch DG, Bennett LD, Duncan JL, Weleber RG, Pennesi ME (2016) Long-term follow-up of patients with retinitis pigmentosa receiving intraocular ciliary neurotrophic factor implants. Am J Ophthalmol 170:10-14. CrossRef Medline

Blanks JC, Johnson LV (1983) Selective lectin binding of the developing mouse retina. J Comp Neur 221:31-41. CrossRef Medline

Chang B, Hawes NL, Hurd RE, Davisson MT, Nusinowitz S, Heckenlively JR (2002) Retinal degeneration mutants in the mouse. Vis Res 42:517-525. Medline

Chang B, Hawes NL, Pardue MT, German AM, Hurd RE, Davisson MT, Nusinowitz S, Rengarajan K, Boyd AP, Sidney SS, Phillips MJ, Stewart RE, Chaudhury R, Nickerson JM, Heckenlively JR, Boatright JH (2007) Two mouse retinal degenerations caused by missense mutations in the beta-subunit of rod cGMP phosphodiesterase gene. Vis Res 47:624-633. CrossRef Medline

Cheng DL, Greenberg PB, Borton DA (2017) Advances in Retinal Prosthetic Research: A Systematic Review of Engineering and Clinical Characteristics of Current Prosthetic Initiatives. Curr Eye Res 42:334-347. Medline

Chew EY, Clemons TE, Peto T, Sallo FB, Ingerman A, Tao W, Singerman L, Schwartz SD, Peachey NS, Bird AC; MacTel-CNTF Research Group (2015) Ciliary neurotrophic factor for macular telangiectasia type 2: results from a phase 1 safety trial. Am J Ophthalmol 159:659-666.e651. CrossRef 
Cideciyan AV, Jacobson SG, Beltran WA, Sumaroka A, Swider M, Iwabe S, Roman AJ, Olivares MB, Schwartz SB, Komáromy AM, Hauswirth WW, Aguirre GD (2013) Human retinal gene therapy for Leber congenital amaurosis shows advancing retinal degeneration despite enduring visual improvement. Proc Natl Acad Sci USA 110:E517-E525. CrossRef Medline

Food and Drug Administration (2017) FDA approves novel gene therapy to treat patients with a rare form of inherited vision loss. FDA news release. Available at: https://www.fda.gov/NewsEvents/ Newsroom/PressAnnouncements/ucm589467.htm.

Hageman GS, Johnson LV (1986) Biochemical characterization of the major peanut-agglutinin-binding glycoproteins in vertebrate retinae. J Comp Neur 249:499-510. CrossRef

Hartong DT, Berson EL, Dryja TP (2006) Retinitis pigmentosa. Lancet 368:1795-1809. CrossRef Medline

Hauswirth WW, Aleman TS, Kaushal S, Cideciyan AV, Schwartz SB, Wang L, Conlon TJ, Boye SL, Flotte TR, Byrne BJ, Jacobson SG (2008) Treatment of leber congenital amaurosis due to RPE65 mutations by ocular subretinal injection of adeno-associated virus gene vector: short-term results of a phase I trial. Hum Gene Ther 19:979-990. CrossRef

Hellman M, Arumäe U, Yu LY, Lindholm P, Peränen J, Saarma M, Permi P (2011) Mesencephalic astrocyte-derived neurotrophic factor (MANF) has a unique mechanism to rescue apoptotic neurons. J Biol Chem 286:2675-2680. CrossRef

Henderson MJ, Richie CT, Airavaara M, Wang Y, Harvey BK (2013) Mesencephalic astrocyte-derived neurotrophic factor (MANF) secretion and cell surface binding are modulated by KDEL receptors. J Biol Chem 288:4209-4225. CrossRef Medline

Jacobson SG, Cideciyan AV, Roman AJ, Sumaroka A, Schwartz SB, Heon E, Hauswirth WW (2015) Improvement and decline in vision with gene therapy in childhood blindness. N Engl J Med 372:19201926. CrossRef Medline

Kang K, Tarchick MJ, Yu X, Beight C, Bu P, Yu M (2016) Carnosic acid slows photoreceptor degeneration in the Pde6b(rd10) mouse model of retinitis pigmentosa. Sci Rep 6:22632. CrossRef Medline

LaVail MM, Battelle BA (1975) Influence of eye pigmentation and light deprivation on inherited retinal dystrophy in the rat. Exp Eye Res 21:167-192. Medline

Li Y, Tao W, Luo L, Huang D, Kauper K, Stabila P, Lavail MM, Laties AM, Wen R (2010) CNTF induces regeneration of cone outer segments in a rat model of retinal degeneration. PLoS One 5:e9495. CrossRef

Lindahl M, Danilova T, Palm E, Lindholm P, ,Võikar V, Hakonen E, Ustinov J, Andressoo JO, Harvey BK, Otonkoski T, Rossi J, Saarma M (2014) MANF is indispensable for the proliferation and survival of pancreatic $\beta$ cells. Cell Rep 7:366-375. CrossRef Medline

Lindahl M, Saarma M, Lindholm P (2017) Unconventional neurotrophic factors CDNF and MANF: structure, physiological functions and therapeutic potential. Neurobiol Dis 97:90-102. CrossRef Medline

Lindholm P, Saarma M (2010) Novel CDNF/MANF family of neurotrophic factors. Dev Neurobiol 70:360-371. CrossRef Medline

Lindholm P, Voutilainen MH, Laurén J, Peränen J, Leppänen VM, Andressoo JO, Lindahl M, Janhunen S, Kalkkinen N, Timmusk T, Tuominen RK, Saarma M (2007) Novel neurotrophic factor CDNF protects and rescues midbrain dopamine neurons in vivo. Nature 448:73-77. CrossRef Medline

Lindholm P, Peränen J, Andressoo JO, Kalkkinen N, Kokaia Z, Lindvall O, Timmusk T, Saarma M (2008) MANF is widely expressed in mammalian tissues and differently regulated after ischemic and epileptic insults in rodent brain. Mol Cell Neurosci 39: 356-371. CrossRef Medline

Liu C, Li Y, Peng M, Laties AM, Wen R (1999) Activation of caspase-3 in the retina of transgenic rats with the rhodopsin mutation s334ter during photoreceptor degeneration. J Neurosci 19:4778-4785. CrossRef

Liu H, Tang X, Gong L (2015) Mesencephalic astrocyte-derived neurotrophic factor and cerebral dopamine neurotrophic factor: new endoplasmic reticulum stress response proteins. Eur J Pharmacol 750:118-122. CrossRef Medline

Maguire AM, Simonelli F, Pierce EA, Pugh EN Jr, Mingozzi F, Bennicelli J, Banfi S, Marshall KA, Testa F, Surace EM, Rossi S, Lyubarsky A, Arruda VR, Konkle B, Stone E, Sun J, Jacobs J, Dell'Osso L, Hertle R, Ma JX, et al. (2008) Safety and efficacy of gene transfer for Leber's congenital amaurosis. N Engl J Med 358:2240-2248. CrossRef Medline

Mätlik K, Yu LY, Eesmaa A, Hellman M, Lindholm P, Peränen J, Galli E, Anttila J, Saarma M, Permi P, Airavaara M, Arumäe U (2015) Role of two sequence motifs of mesencephalic astrocyte-derived neurotrophic factor in its survival-promoting activity. Cell Death Dis 6:e2032. CrossRef Medline

Neves J, Zhu J, Sousa-Victor P, Konjikusic M, Riley R, Chew S, Qi Y, Jasper H, Lamba DA (2016) Immune modulation by MANF promotes tissue repair and regenerative success in the retina. Science 353:aaf3646. CrossRef Medline

Ohnaka M, Miki K, Gong YY, Stevens R, Iwase T, Hackett SF, Campochiaro PA (2012) Long-term expression of glial cell linederived neurotrophic factor slows, but does not stop retinal degeneration in a model of retinitis pigmentosa. J Neurochem 122: 1047-1053. CrossRef Medline

Panchision DM, Martin-DeLeon PA, Takeshima T, Johnston JM, Shimoda K, Tsoulfas P, McKay RD, Commissiong JW (1998) An immortalized, type-1 astrocyte of mesencephalic origin source of a dopaminergic neurotrophic factor. J Mol Neurosci 11:209-221. CrossRef Medline

Pang JJ, Boye SL, Kumar A, Dinculescu A, Deng W, Li J, Li Q, Rani A, Foster TC, Chang B, Hawes NL, Boatright JH, Hauswirth WW (2008) AAV-mediated gene therapy for retinal degeneration in the rd10 mouse containing a recessive PDEbeta mutation. Invest Ophthalmol Vis Sci 49:4278-4283. CrossRef Medline

Pang JJ, Dai X, Boye SE, Barone I, Boye SL, Mao S, Everhart D, Dinculescu A, Liu L, Umino Y, Lei B, Chang B, Barlow R, Strettoi E, Hauswirth WW (2011) Long-term retinal function and structure rescue using capsid mutant AAV8 vector in the rd10 mouse, a model of recessive retinitis pigmentosa. Mol Ther 19:234-242. CrossRef

Parkash V, Lindholm P, Peränen J, Kalkkinen N, Oksanen E, Saarma M, Leppänen VM, Goldman A (2009) The structure of the conserved neurotrophic factors MANF and CDNF explains why they are bifunctional. Protein Eng Des Sel 22:233-241. CrossRef Medline

Petrova P, Raibekas A, Pevsner J, Vigo N, Anafi M, Moore MK, Peaire AE, Shridhar V, Smith DI, Kelly J, Durocher Y, Commissiong JW (2003) MANF: a new mesencephalic, astrocyte-derived neurotrophic factor with selectivity for dopaminergic neurons. J Mol Neurosci 20:173-188. Medline

Phillips MJ, Walker TA, Choi HY, Faulkner AE, Kim MK, Sidney SS, Boyd AP, Nickerson JM, Boatright JH, Pardue MT (2008) Tauroursodeoxycholic acid preservation of photoreceptor structure and function in the rd10 mouse through postnatal day 30 . Invest Ophthalmol Vis Sci 49:2148-2155. CrossRef Medline

RetNet (2018) Summaries of genes and loci causing retinal diseases. Available at: https://sph.uth.edu/retnet/sum-dis.htm.

Sallo FB, Leung I, Clemons TE, Peto T, Chew EY, Pauleikhoff D, Bird AC; MacTel-CNTF Research Group (2018) Correlation of structural and functional outcome measures in a phase one trial of ciliary neurotrophic factor in type 2 idiopathic macular telangiectasia. Retina 38 [Suppl1]:S27-S32. CrossRef

Sieving PA, Caruso RC, Tao W, Coleman HR, Thompson DJ, Fullmer KR, Bush RA (2006) Ciliary neurotrophic factor (CNTF) for human retinal degeneration: phase I trial of CNTF delivered by encapsulated cell intraocular implants. Proc Natl Acad Sci USA 103:38963901. CrossRef Medline

Song Y, Zhao L, Tao W, Laties AM, Luo Z, Wen R (2003) Photoreceptor protection by cardiotrophin-1 in transgenic rats with the rhodopsin mutation s334ter. Invest Ophthalmol Vis Sci 44:40694075. Medline 
Talcott KE, Ratnam K, Sundquist SM, Lucero AS, Lujan BJ, Tao W, Porco TC, Roorda A, Duncan JL (2011) Longitudinal study of cone photoreceptors during retinal degeneration and in response to ciliary neurotrophic factor treatment. Invest Ophthalmol Vis Sci 52:2219-2226. CrossRef Medline

Tao W, Wen R, Goddard MB, Sherman SD, O'Rourke PJ, Stabila PF, Bell WJ, Dean BJ, Kauper KA, Budz VA, Tsiaras WG, Acland GM, Pearce-Kelling S, Laties AM, Aguirre GD (2002) Encapsulated cell-based delivery of CNTF reduces photoreceptor degeneration in animal models of retinitis pigmentosa. Invest Ophthalmol Vis Sci 43:3292-3298. Medline

Voutilainen MH, Bäck S, Pörsti E, Toppinen L, Lindgren L, Lindholm P, Peränen J, Saarma M, Tuominen RK (2009) Mesencephalic astrocyte-derived neurotrophic factor is neurorestorative in rat model of Parkinson's disease. J Neurosci 29:9651-9659. CrossRef Medline

Voutilainen MH, Arumäe U, Airavaara M, Saarma M (2015) Therapeutic potential of the endoplasmic reticulum located and secreted CDNF/MANF family of neurotrophic factors in Parkinson's disease. FEBS Lett 589:3739-3748. CrossRef Medline

Wang H, Ke Z, Alimov A, Xu M, Frank JA, Fang S, Luo J (2014) Spatiotemporal expression of MANF in the developing rat brain. PLoS One 9:e90433. CrossRef Medline

Wen R, Song Y, Kjellstrom S, Tanikawa A, Liu Y, Li Y, Zhao L, Bush RA, Laties AM, Sieving PA (2006) Regulation of rod phototrans- duction machinery by ciliary neurotrophic factor. J Neurosci 26 : 13523-13530. CrossRef Medline

Wen R, Tao W, Li Y, Sieving PA (2012) CNTF and retina. Prog Retin Eye Res 31:136-151. CrossRef Medline

Xia X, Li Y, Huang D, Wang Z, Luo L, Song Y, Zhao L, Wen R (2011) Oncostatin $\mathrm{M}$ protects rod and cone photoreceptors and promotes regeneration of cone outer segment in a rat model of retinal degeneration. PLoS One 6:e18282. CrossRef

Yang S, Huang S, Gaertig MA, Li XJ, Li S (2014) Age-dependent decrease in chaperone activity impairs MANF expression, leading to Purkinje cell degeneration in inducible SCA17 mice. Neuron 81:349-365. CrossRef Medline

Yavarna T, Al-Dewik N, Al-Mureikhi M, Ali R, Al-Mesaifri F, Mahmoud L, Shahbeck N, Lakhani S, AlMulla M, Nawaz Z, Vitazka P, Alkuraya FS, Ben-Omran T (2015) High diagnostic yield of clinical exome sequencing in Middle Eastern patients with Mendelian disorders. Hum Genet 134:967-980. CrossRef Medline

Zhang K, Hopkins JJ, Heier JS, Birch DG, Halperin LS, Albini TA, Brown DM, Jaffe GJ, Tao W, Williams GA (2011) Ciliary neurotrophic factor delivered by encapsulated cell intraocular implants for treatment of geographic atrophy in age-related macular degeneration. Proc Natl Acad Sci USA 108:6241-6245. CrossRef Medline 